\title{
Effects of deficit irrigation on daily and seasonal variations of trunk sap flow and its growth in Calligonum arborescens
}

\author{
LiShan SHAN ${ }^{1}$, Yi LI ${ }^{1 *}$, RuiFeng ZHAO ${ }^{2}$, XiMing ZHANG ${ }^{3}$ \\ ${ }^{1}$ Forestry Department, Gansu Agricultural University, Lanzhou 730070, China; \\ ${ }^{2}$ College of Geography and Environment Science, Northwest Normal University, Lanzhou 730070, China; \\ ${ }^{3}$ Xinjiang Institute of Ecology and Geography, Chinese Academy of Sciences, Urumqi 830011, China
}

\begin{abstract}
Water deficit in arid and semiarid regions affects whole-plant sap flow and leaf-level water relations. The objectives of this study were to clarify how sap flow of Calligonum arborescens responds to different drought stress conditions and to understand its acclimation mechanism to drought environments. A field experiment was conducted for $C$. arborescens during the growing season to evaluate the effects of deficit irrigation on the daily and seasonal variations of trunk sap flow in the shelterbelt along the Tarim Desert Highway, Xinjiang, China. Three different water regimes $\left(2,380,1,960\right.$ and $\left.1,225 \mathrm{~m}^{3} / \mathrm{hm}^{2}\right)$ were applied at different stages of plant growth. From 1 May to 30 October 2007, a heat-balance stem flow gauge was used to monitor the sap flow dynamics of $C$. arborescens under different water regimes. Atmospheric evaporation demand and soil moisture conditions for differentially irrigated $C$. arborescens were also monitored. The result showed that sap flow exhibited a clear diurnal pattern regardless of treatments; the diurnal patterns of sap flow and vapour pressure deficit were very similar under different water regimes and growing seasons, while the slope of the linear regression of this correlation confirmed an increasing water regime. The sap flow decreased under reduced water regimes and there was nocturnal sap flow regardless of water regimes, which was mainly contributed to nocturnal transpiration and water recharge. The sap flow peaked before midnight and dropped afterwards with obviously higher values in summer than in other seasons. It is speculated that the water consumption of $C$. arborescens during the day can be supplemented through the sap flow at night, which increased with increasing irrigation amount. Net radiation was the most significant correlated factor that influenced sap flow velocity and transpiration under different water regimes $\left(R^{2}>0.719\right)$. Compared with the commonly practiced water regime, the growth of $C$. arborescens was significantly slower in the stress deficit irrigation, but not significantly different from that in the moderate deficit irrigation. The moderate deficit irrigation would not affect the stability of the shelterbelt and was a more efficient use of water resources compared with the current watering amount.
\end{abstract}

Keywords: Calligonum arborescens; sap flow; environmental factor; growth parameter; Tarim Desert Highway

Citation: LiShan SHAN, Yi LI, RuiFeng ZHAO, XiMing ZHANG. 2013. Effects of deficit irrigation on daily and seasonal variations of trunk sap flow and its growth in Calligonum arborescens. Journal of Arid Land, 5(2): 233-243.

A declining supply of water is a major threat to plants in arid and semi-arid regions. In the Taklimakan Desert of Northwest China, where the mean annual precipitation $(36.6 \mathrm{~mm})$ does not meet evapotranspirative demand $(3,638.6 \mathrm{~mm})$, plants may undergo long-term water deficiencies because of a long dry season. In 2002, a 436-km shelterbelt was constructed along the
Tarim Desert Highway. After the shelterbelt was established, the groundwater is the only water resource for irrigation. The shelterbelt consumed large amount of water due to the hyperarid environment. Moreover, the increasing of potential evapotranspiration triggered by global warming caused more water loss. All these threatened the water security of the region. As a

*Corresponding author: Yi LI (E-mail: liyi@gsau.edu.cn)

Received 2012-07-11; revised 2012-09-06; accepted 2012-11-16

(C) Xinjiang Institute of Ecology and Geography, Chinese Academy of Sciences, Science Press and Springer-Verlag Berlin Heidelberg 2013 
result, restoring the stability and maintaining the sustainability of the shelterbelt by minimizing its impact on limited water resources have become an urgent and important question that can only be scientifically answered by studying the effect of a reduced water supply on plant water use and growth condition.

Stem sap flow is the water and nutrient flow through stems and its main component is water (Xu et al., 2008a). The stem flow accumulation was found to be equal to the daily transpiration and water consumption by plants (Lagergren and Lindroth, 2002). Therefore, at the daily scale, stem sap flow accurately reflects individual plant transpiration and water use although it may be influenced by environmental factors (i.e. solar radiation, relative humidity, and soil moisture) and biophysical processes (soil water deficit) (Vetessy et al., 1995).

Soil water deficit in arid and semi-arid regions inevitably influences transpiration and sap flow dynamics (Zhang et al., 2011). Walter and Box (1983) found that the transpiration rates of Tamarix sp. were high and peaked at noon under ample water conditions; however, the diurnal transpiration displayed a bimodal pattern under severe water stress. Xie et al. (2008a, b) found that the stem sap flow of Haloxylon ammodendron and Tamarix ramosissima varied with irrigations. With heavy irrigation, the diurnal stem sap flow showed a single peak curve with higher variations; while with less irrigation, the diurnal variation changed to a bimodal pattern with small variations. Sap flow usually displays variations over time and seasons. The curve of the day-time sap flow is bimodal with an S-shaped accumulative process. The sap flow during day time is significantly higher than that during night time. The average diurnal trunk sap flow of H. ammodendron in April is about two times as much as in any other month. After May, with the soil water content decreases, there is no obvious difference in sap flow between day time and night time, and the accumulative process curve is linear (Sun et al., 2010).

A dominant portion $(99.8 \%)$ of stem sap flow is transpired. By accurately measuring stem sap flow, we can determine the water loss of plant transpiration. Many methods were developed to determine stem sap flow (Zhang et al., 2005). For example, heat quality method was used by many researchers to estimate the water consumption of forest transpiration through measuring stem sap flow rate, analyzing the relationship between stem sap flow rate and environmental factors. At present, this method has become more and more common in estimating water use quality of trees (Zhang et al., 2007; Zhou et al., 2008). Stem heat balance is an advanced approach to determine stem sap flow. Compared with other thermal dynamic methods, this method is more welcomed because of its high precision and good suitability for plants of smaller diameters (Zhang et al., 2007). Therefore, sap flow measuring gauges based on heat-balance principles (Baker and Van Bavel, 1987) have proved to be reliable for continuous measurement, and have been widely used to estimate tree transpiration and investigate physiological and environmental controls on water use (Dragoni et al., 2005; Burgess, 2006). This method has become an important tool not only for research in plant-water relations but also for irrigation management (Ferrara and Flore, 2003).

Calligonum arborescens is classified as a drought-tolerant shrub; it is often used as a pioneer species for reducing sand erosion, and is able to grow rapidly in the shelterbelt along the Tarim Desert Highway. C. arborescens is able to withstand recurrent droughts as its leaves are degenerative assimilating shoots characterized with low transpiration rate (Su et al., 2003), low light saturation, high light compensation (Su and Yan, 2006), and low water potential (Dhief et al., 2008). C. arborescens has certain structural features and an active mechanism to minimize water loss under water stress. However, little is known about the response of the plant to reduced water availability, particularly in the extremely arid Taklimakan Desert. Current irrigation management of the shelterbelt along the Tarim Desert Highway operates in ignorance of the effects of changes in water availability on $C$. arborescens survival. Therefore, by measuring the seasonal and diurnal transpiration of $C$. arborescens and studying its growth under different water regimes, we aimed to characterize the water use and growth conditions of $C$. arborescens, and gain an understanding of the temporal variations in these parameters. The knowledge obtained from this study will be able to provide a valuable insight into efficiently managing the shelterbelt along the Tarim Desert Highway and provide a theoretical basis for the 
sustainable use of the limited groundwater resources in semi-arid and arid regions.

\section{Materials and methods}

\subsection{Study area}

This study was conducted with six-year-old $C$. arborescens plants grown in the shelterbelt along the Tarim Desert Highway, Xinjiang, China (Fig. 1) during the growing season. The annual average temperature in the study area is $12.4^{\circ} \mathrm{C}$. July, the hottest month in a year, has an average temperature of $28.2^{\circ} \mathrm{C}$, while December, the coldest month, has an average temperature of $-8.1^{\circ} \mathrm{C}$. The recorded highest temperature is $45.6^{\circ} \mathrm{C}$ and the recorded lowest is $-22.2^{\circ} \mathrm{C}$. The annual sunshine hours are approximately $2,571 \mathrm{~h}$. The mean annual precipitation is $36.6 \mathrm{~mm}$, and the average relative humidity is $29.4 \%$. The potential evapotranspiration rate is $3,638.6 \mathrm{~mm}$. The average wind speed is $2.5 \mathrm{~m} / \mathrm{s}$, while the highest is $24.0 \mathrm{~m} / \mathrm{s}$. The windy season with an average wind velocity of $3.2 \mathrm{~m} / \mathrm{s}$ lasts from April to August, during which sandstorms occur frequently. There are about 60 days with heavy winds per year, 74 days with drifting dust and 45 days with blowing wind sand. Soil salinity ranges from 1.26 to $1.63 \mathrm{~g} / \mathrm{kg}$. The subsoil layer is occasionally clay, with a thickness of $20-60 \mathrm{~cm}$, below the aeolian sandy soil.

\subsection{Physical environment}

Climatic variables were monitored using an automatic weather station (Campbell Scientific Inc., Utah, USA) installed in an open field close to the study area from 1 May to 30 October 2007. Thirty-minute averages of all variables including solar radiation (total and net), air temperature, air humidity and wind velocity at $2 \mathrm{~m}$ above ground were recorded using a CR10 data logger (Campbell Scientific Inc., Utah, USA). Total precipitation during the study period was $13.4 \mathrm{~mm}$ (Fig. 2a). Maximum air temperature and maximum vapour pressure deficit (VPD) were illustrated in Fig. 2b and c, respectively. During the study period, maximum air temperature was recorded in July, with an average of around $31.26^{\circ} \mathrm{C}$. The lowest average of around $12.81^{\circ} \mathrm{C}$ was recorded in October. Maximum VPD was highest in July and lowest in June. VPD was calculated by the equation which is given by Campbell and Norman (1998):

$$
V P D=a e^{\left(\frac{b T}{T+c}\right)}(1-R H) .
$$

Where $T$ is daily average air temperature observed at 2-m height; $R H$ is average daily relative humidity observed at $2-\mathrm{m}$ height; $a, b$ and $c$ is $0.611 \mathrm{kPa}$, $17.502^{\circ} \mathrm{C}$ and $240.97^{\circ} \mathrm{C}$, respectively.

\subsection{Irrigation treatments}

Six-year-old $C$. arborescens individuals from the shelterbelt along the Tarim Desert Highway were se-

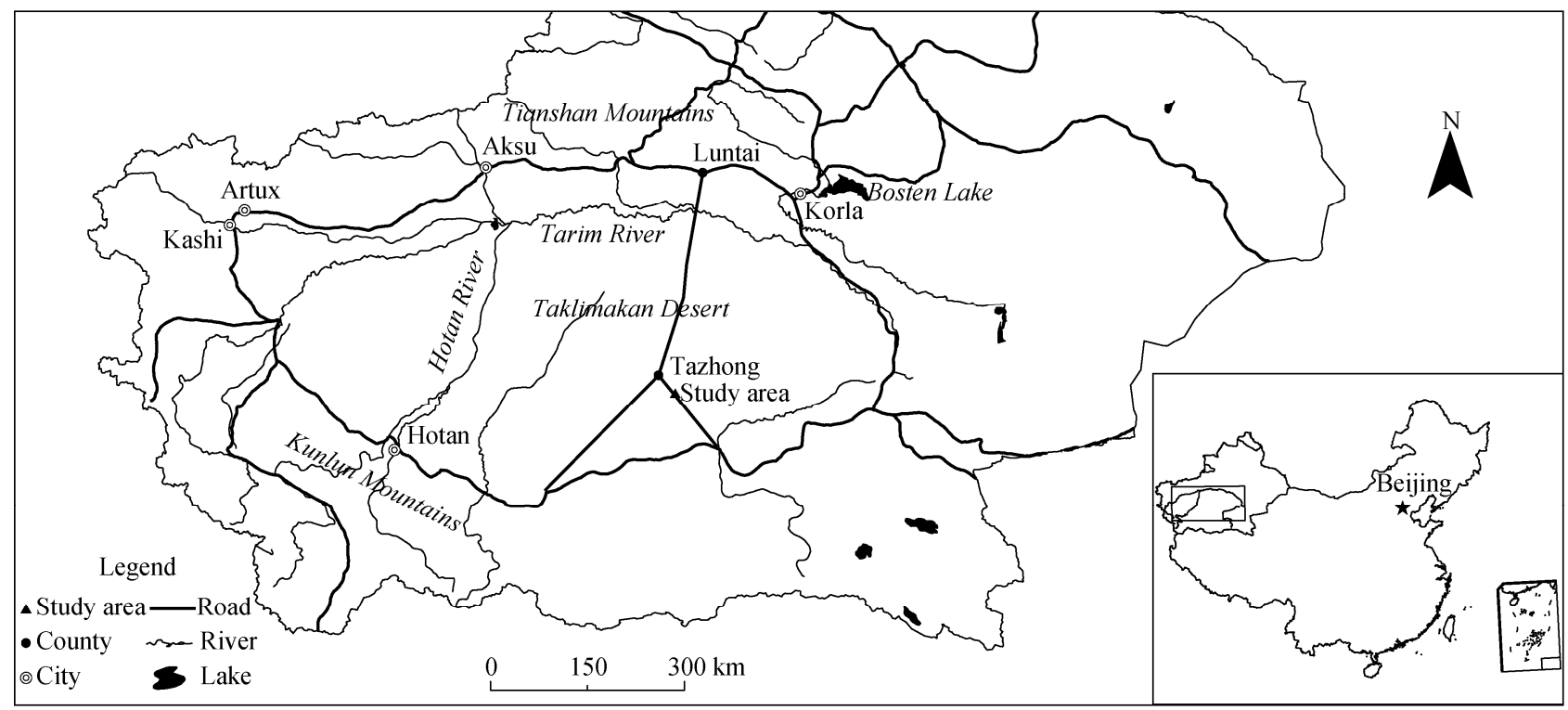

Fig. 1 Location of the study area in the Taklimakan Desert 

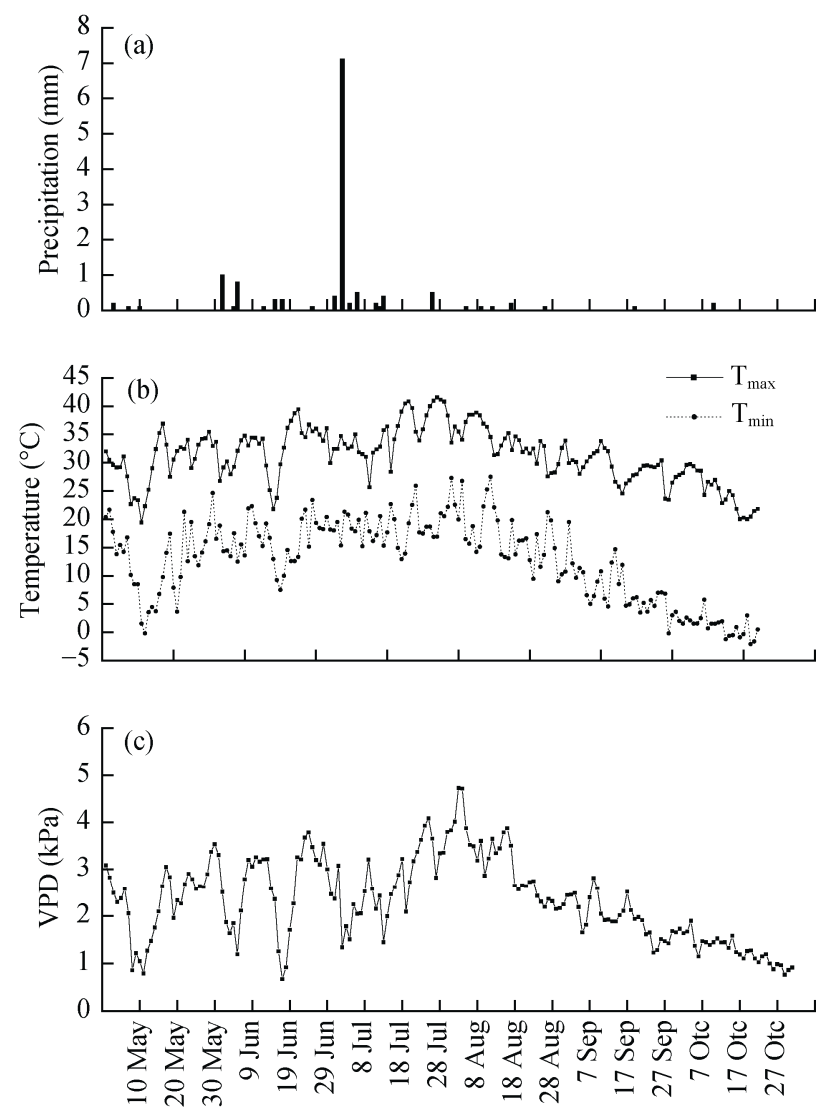

Fig. 2 Daily precipitation, maximum $\left(T_{\max }\right)$ and minimum $\left(T_{\min }\right)$ daily temperatures, and daily vapour pressure deficit (VPD) during the study period

lected in this study and they were planted in rows $2 \mathrm{~m}$ apart, at a spacing of $1 \mathrm{~m}$. Considering the variations in microsite and plant growth status, three shelterbelts of $1,000 \mathrm{~m}^{2}(100 \mathrm{~m} \times 10 \mathrm{~m})$ were selected for different irrigation treatments, three treatments with various capacities of irrigation were set as follows: (1) 2,380 $\mathrm{m}^{3} / \mathrm{hm}^{2}$ for normal water supply (CK, the control of this study), consistent with the current irrigation amount used in the shelterbelt along the Tarim Desert Highway; (2) $1,960 \mathrm{~m}^{3} / \mathrm{hm}^{2}$ for moderate deficit irrigation (MD); and (3) $1,225 \mathrm{~m}^{3} / \mathrm{hm}^{2}$ for stress deficit irrigation (SD), the minimum irrigation amount below which $C$. arborescensb began to die. The site was irrigated every 15 days by drip irrigation in May, June, September, October, respectively. It was irrigated every 10 days by drip irrigation in July and August. The $1^{\text {st }}$ irrigation started on 1 May and the last irrigation was applied on 15 October, with a total of 14 irrigation times.

\subsection{Sap flow measurement}

Sap flow was monitored within the stems of CK, MD and SD plants using the Flow32 sap flow measure- ment system (Steinberg et al., 1989). The stems selected for measuring sap flow should be straight with smooth skins, and dead skin of the stems should be scraped off without destroying the stems. The selected three plants should be similar in height and crown diameter (approximately $2 \mathrm{~m}$ in height with a crown span of $9 \mathrm{~m}^{2}$ ), with straight stem of $3.2 \mathrm{~cm}$ in diameter for sap flow measurement. Then, the stems were polished using sand paper. The diameter of each stem in which the sap flow probe was installed was measured with vernier calipers. In order to increase contact between the probe and the stem, the stems were coated with mixed oil before installing probes. The probes were installed at the base of stem, and adiabatic material was installed to seal up both ends of the probes after the stem and the probe were in tight contact. To avoid the effect of solar radiation on probe temperature, the safeguarded sheath was wrapped outside of the probe after installing. The signal line of the probe was connected to a data acquisition unit (Delta-T Logger) which also had a corresponding interface to communicate with a computer. A 12-volt battery was used to supply power to both the probes and data acquisition unit. Then, the cross sectional area of the plant, start time, intervals of data recording, and other parameters were imported into the data acquisition unit through a computer. Sap flow was monitored at an interval of 15 minutes from May to October.

\subsection{Soil water measurement}

Next to each plant for sap flow measurement, soil moisture content was determined by the gravimetric method at $0.2-\mathrm{m}$ intervals in the soil depth of $0-3 \mathrm{~m}$. Measurement of soil moisture was done on several occasions from May to October.

\subsection{Growth parameter measurement}

Ten plants in each treatment were measured for trunk diameter. In addition, twelve twigs were selected in four directions of every plant and were measured for length and diameter (three replications). These measurements were taken twice, at the beginning and end of the experiment, and the differences between two measurements of each variable were used as growth indicator parameters.

\subsection{Statistical analysis}

Means and standard errors were calculated for three replicates from each treatment. Statistical analysis was conducted using SPSS software (SPSS 13.0). The sta- 
tistical significance of the difference between means was determined by LSD test. Statistical comparisons were considered significant at $P=0.05$. The regression lines were tested for homogeneity of error and coefficients were compared for significance. All graphical constructions were completed using the Origin 7.0 software package.

\section{Results}

\subsection{Seasonal variation in soil moisture content under different water regimes}

Soil moisture content throughout the growing season indicated a similar unimodal curve pattern regardless of water regimes (Fig. 3). In addition, the minimum soil moisture contents of different irrigation treatments were seen in July. This was probably due to extreme drought weather condition during the summer season in the Taklimakan Desert. No significant differences in soil moisture content were found either between $\mathrm{CK}$ and MD or between MD and SD; however, the soil moisture content was significantly lower in SD than in CK during the study period.

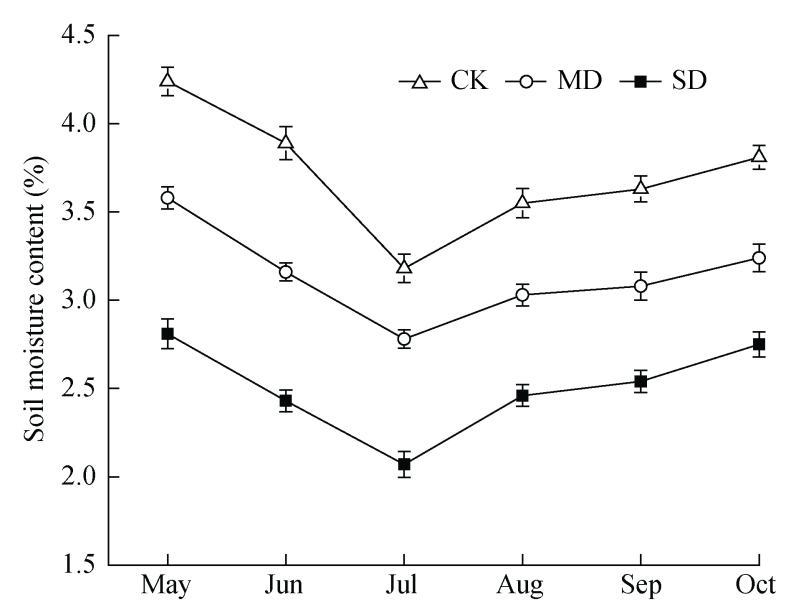

Fig. 3 Seasonal variation in soil moisture content under different water regimes

\subsection{Variations of trunk sap flow under different water regimes}

Sap flow showed a clear diurnal pattern regardless of treatments: a steep morning increase led to the maximum rates achieved at about midday (when vapour pressure deficit was at its maximum), followed by a sustained gradual decrease until late afternoon (Figs. 4a-f). The daily sap flow-activity period displayed a pattern that increased from May to July but decreased from July to October.

Throughout this study, the nocturnal sap flow activity was recorded under different water regimes (Figs. 4a-f). In comparison with diurnal stem sap flow, the nocturnal sap flow was lower and increased with raised irrigation amount. The sap flow kept a higher level at early night (20:00-00:00) under different irrigation amounts but tended to be stable at midnight. The nocturnal water recharge was dissimilar during different growing periods in which the nocturnal sap flow reached a maximum in July while it dropped to zero at the end of growing season regardless of treatments. However, the variation in sap flow throughout the growing period indicated that sap flow decreased under reduced water regimes, particularly in the summer. The hourly sap flux density measured was strongly and positively correlated with vapour pressure deficit under different water regimes, but the slope was consistently steeper with the increase of irrigation regimes (Fig. 5).

\subsection{Monthly sap flow under different irrigation treatments}

Monthly sap flow or water consumption differed significantly among treatments, except for the late fall (Fig. 6). The monthly water consumption reached the maximum rate in July and then decreased to the minimum rate in October regardless of irrigation treatments. This could be attributed to the seasonal variation in the net radiation which showed a unimodal response with the peak value that occurred in July, while soil moisture content decreased to the minimum in July (Fig. 7a). At the same time, the monthly variation in air temperature may be another factor that also affected sap flow (Fig. 7b). The monthly variation in air temperature followed the similar pattern as solar radiation did, with the highest daily average of $27.87^{\circ} \mathrm{C}$ in July. The average temperature of the growing period was $22.64^{\circ} \mathrm{C}$ and the persistently high temperature caused a vapour pressure deficit between the leaf and the air, and increased sap flow velocity as well. However, the assimilating shoot began to shed in the late fall, which may reduce sap flow velocity. 

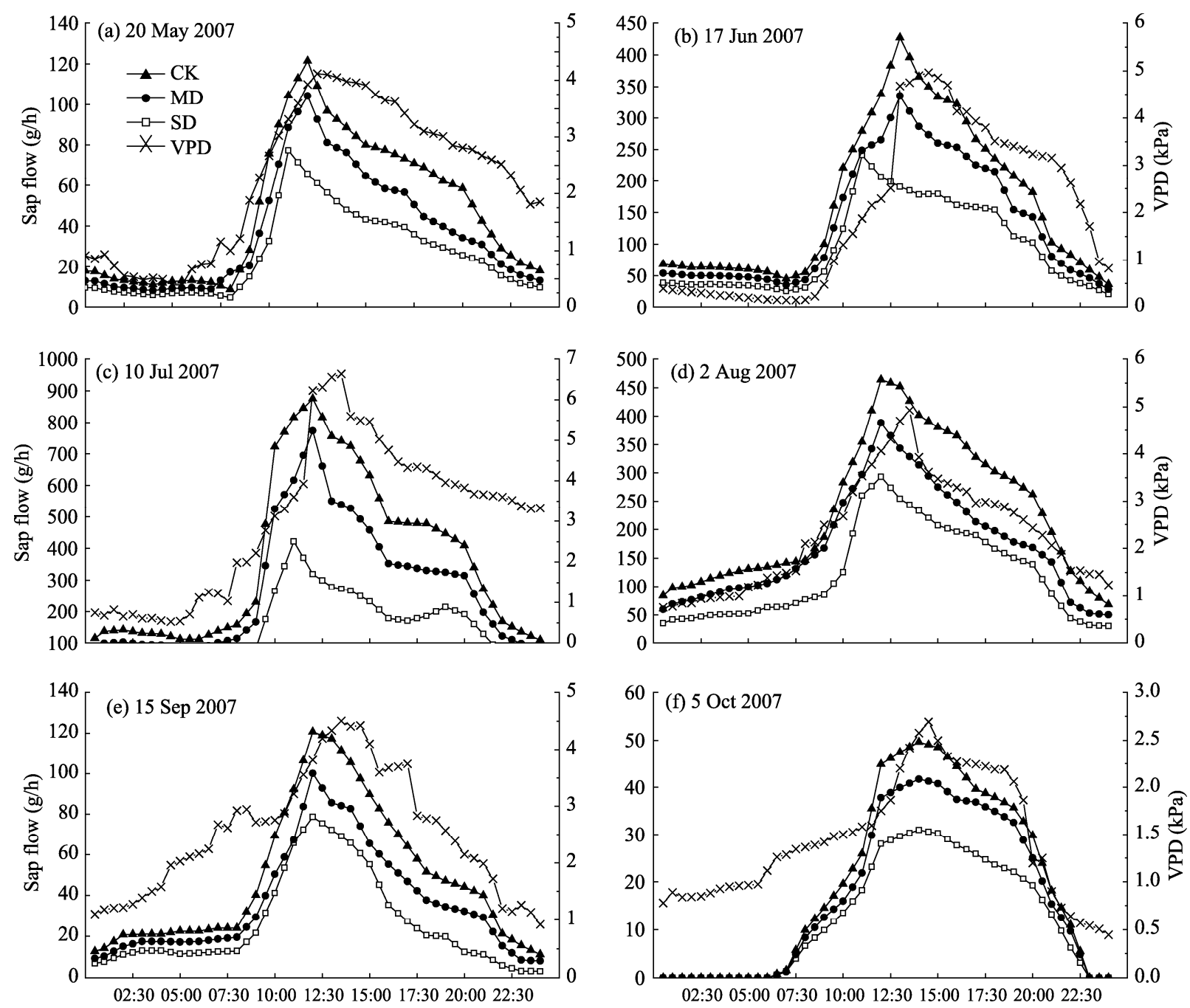

Fig. 4 Diurnal patterns of sap flow and vapour pressure deficit (VPD) in the $C$. arborescens throughout the growing season

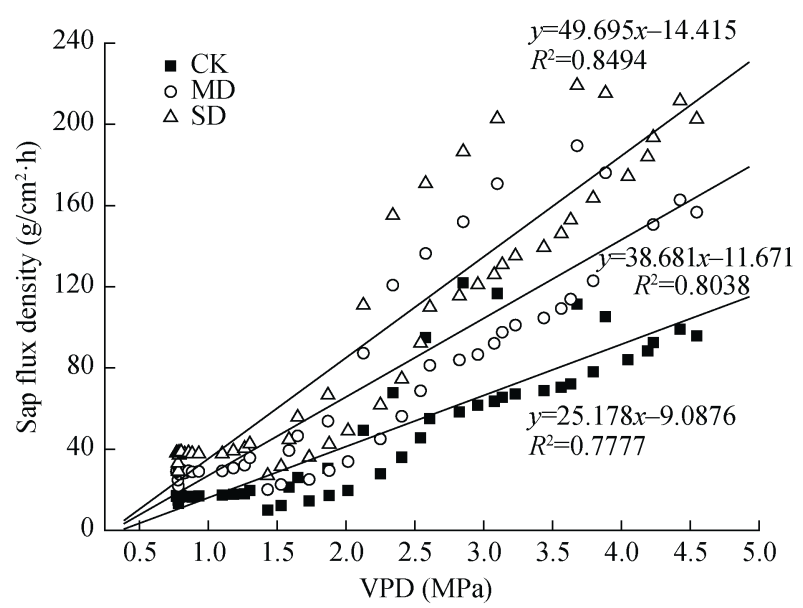

Fig. 5 Relationship between sap flux density and vapour pressure deficit (VPD) in the $C$. arborescens throughout the growing season

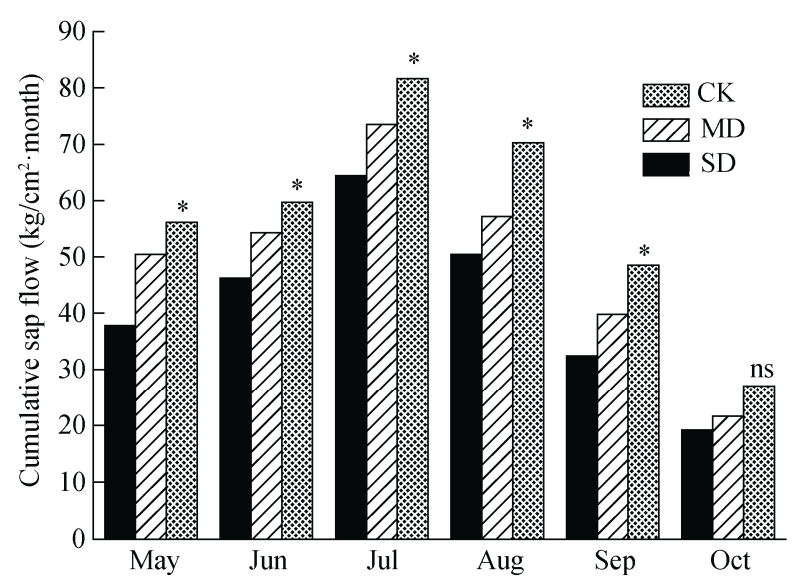

Fig. 6 Monthly cumulative sap flow flux in the C. arborescens during the study period. Significance of differences between water regimes was also reported: * indicates significance at $P<0.05$ level; ns means no significance. 


\subsection{Diurnal sap flow and environmental factors}

The variation in sap flow velocity was closely associated with air temperature, wind speed, net radiation and relative humidity under different watering treatments (Fig. 8). The correlation between sap flow ve-

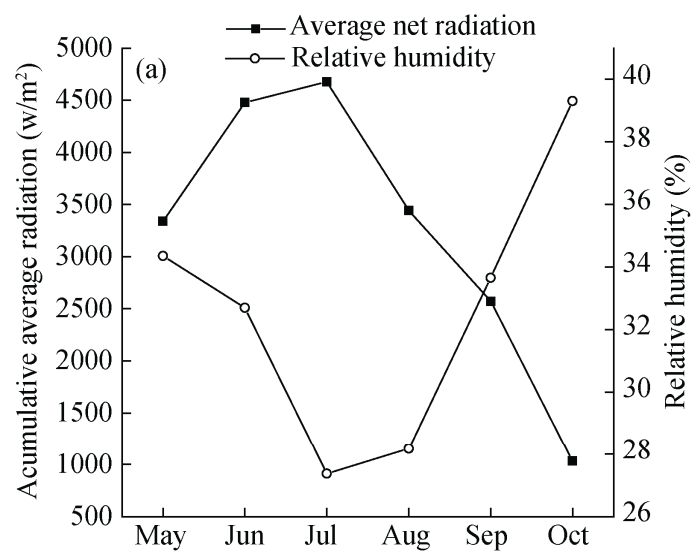

locity and net radiation was highest under different water regimes, with correlation coefficients from 0.719 to 0.765 (Table 1). Although sap flow showed a strong positive relationship with air temperature and wind speed, a significant negative relationship with

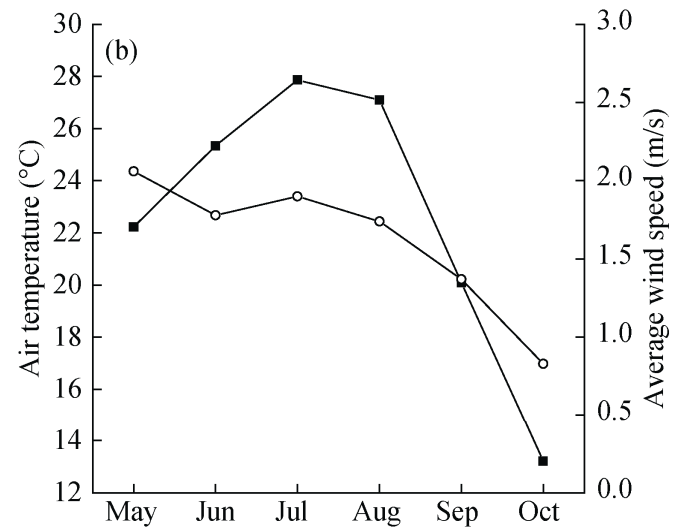

Fig. 7 Seasonal variations in meteorological factors during the study period
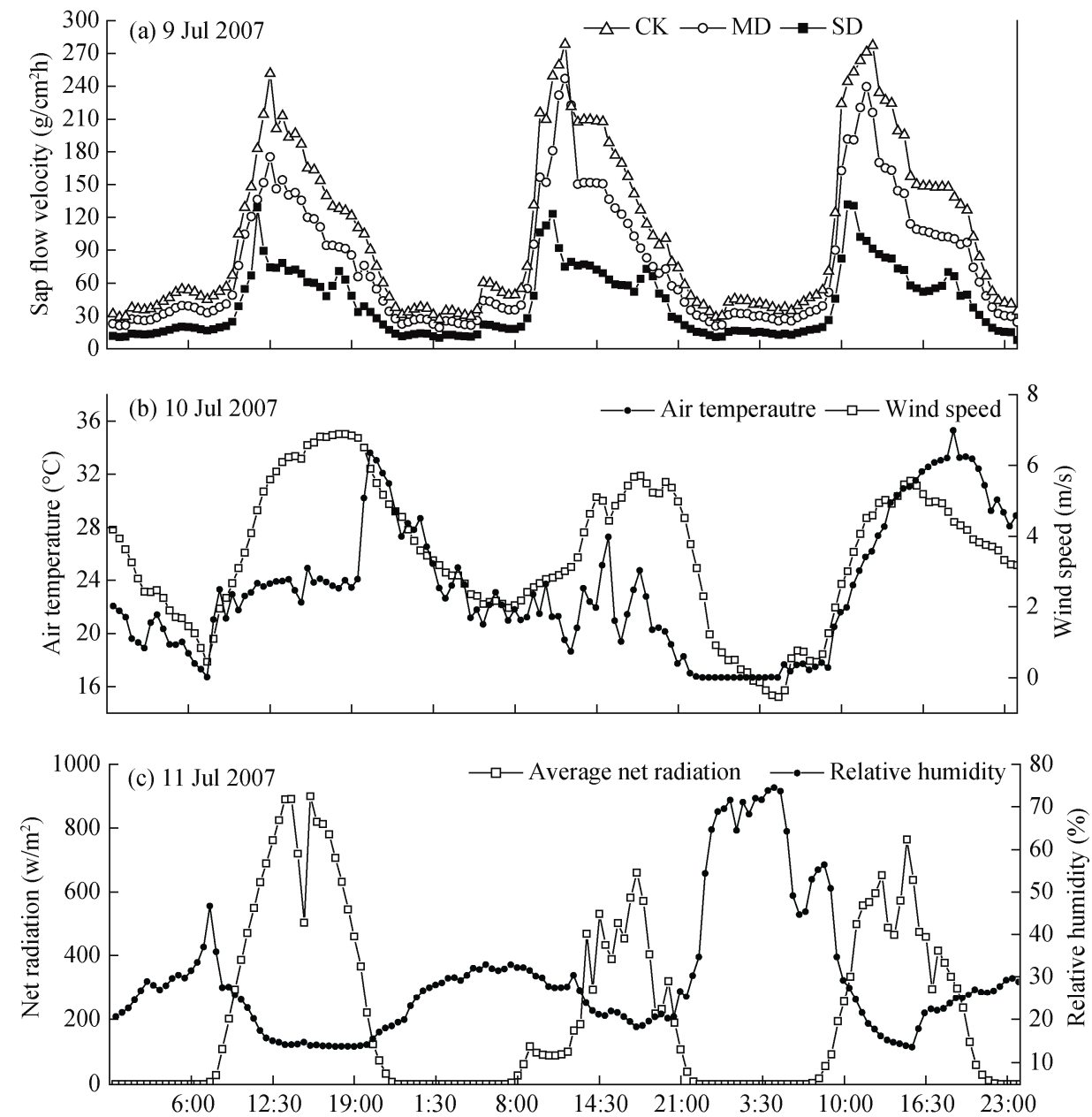

Fig. 8 The diurnal variations in sap flow velocity and meteorological factors during three days under different water regimes 
Table 1 The relationships between sap flow velocity and meteorological factors under different water regimes

\begin{tabular}{cccccc}
\hline Treatment & Total radiation & Net radiation & Temperature & Wind speed & Relative humidity \\
\hline CK & $0.745^{* *}$ & $0.765^{* *}$ & $0.525^{* *}$ & $0.271^{* *}$ & $-0.493^{* *}$ \\
MD & $0.698^{* *}$ & $0.719^{* *}$ & $0.481^{* *}$ & $0.240^{* *}$ & $-0.463^{* *}$ \\
SD & $0.707^{* *}$ & $0.723^{* *}$ & $0.502^{* *}$ & $0.249^{* *}$ & $-0.474^{* *}$ \\
\hline
\end{tabular}

Note: ** denotes significance at $P<0.01$ level.

relative humidity was still found.

The stepwise regressions generated from sap flow velocity $(y)$ to air temperature $\left(x_{1}\right)$, relative humidity $\left(x_{2}\right)$, wind speed $\left(x_{3}\right)$, total radiation $\left(x_{4}\right)$, and net radiation $\left(x_{5}\right)$ suggested that the net radiation had a significant partial correlation with sap flow velocity in SD. However, the net radiation, total radiation, and relative humidity all indicated significant partial correlations with sap flow velocity in CK and MD (Table 2).

Table 2 Regression analysis for diurnal variation of stem sap flow under different water regimes

\begin{tabular}{ccc}
\hline Treatment & Regression equation & $R^{2}$ \\
\hline CK & $y=165.205-1.157 x_{2}-0.607 x_{4}+1.293 x_{5}$ & $0.798^{* *}$ \\
MD & $y=129.139-0.908 x_{2}-0.509 x_{4}+1.051 x_{5}$ & $0.758^{* *}$ \\
SD & $y=30.003+0.137 x_{5}$ & $0.723^{* *}$ \\
\hline
\end{tabular}

Note: ** denotes significance at $P<0.01$ level.

\subsection{Growth responses to different irrigation treat- ments}

The trunk diameters, twig lengths and twig diameters were significantly smaller in plants grown in SD than in those grown in CK and MD (Table 3). However, no significant difference of plant growth was found between MD and CK.

Table 3 The increment of growth parameters under different water regimes

\begin{tabular}{cccc}
\hline \multirow{2}{*}{ Treatment } & Trunk diameter & Twig diameter & Twig length \\
\cline { 2 - 4 } & \multicolumn{3}{c}{$(\mathrm{cm})$} \\
\hline CK & $0.68 \pm 0.08^{\mathrm{a}}$ & $0.06 \pm 0.002^{\mathrm{a}}$ & $12.49 \pm 0.69^{\mathrm{a}}$ \\
$\mathrm{MD}$ & $0.57 \pm 0.02^{\mathrm{a}}$ & $0.06 \pm 0.002^{\mathrm{a}}$ & $11.99 \pm 0.45^{\mathrm{a}}$ \\
$\mathrm{SD}$ & $0.38 \pm 0.05^{\mathrm{b}}$ & $0.04 \pm 0.003^{\mathrm{b}}$ & $9.03 \pm 0.49^{\mathrm{b}}$ \\
\hline
\end{tabular}

Note: Means $( \pm \mathrm{SE})$ within the same row followed by different letters differ significantly at $P<0.05$.

\section{Discussion}

Vapour pressure deficit is an important determinant of whole-plant stem sap flow (Wang et al., 2008). Granier et al. (1992) found that the stem sap flow was sensitive to vapour pressure deficit. Zhang et al. (2011), by using an exponential saturation function to fit the relationship between sap flux density and vapour pressure deficit, found that the fitted curves effectively reflected the sap flow characteristics in different months. In our study, there was a strong similarity between diurnal patterns of sap flow and vapour pressure deficit, which was consistent with Tognetti's findings that there existed significant positive correlations between the sap flow velocity of olive and vapour pressure deficit (Tognetti et al., 2004). It is possible that $C$. arborescens transpiration was likely to be largely controlled by the diffusion or adiabatic term of the Penman-Monteith equation, i.e. the transpiration appeared to be strongly coupled with the surrounding air (Moreno et al., 1996).

The stem sap flow, influenced by plant physiological activities and environmental factors, had an obvious diurnal rhythm in both day and night. When the solar radiation was intense and temperature was high during the daytime, transpiration was high; when photosynthesis stopped at night, transpiration was low (Xu et al., 2008a). The stem sap flow of Haloxylon ammodendron exhibited a distinct diurnal course in the hinterland of Taklimakan Desert. Generally, sap flow was lower at night than during the day (Xu et al., 2008b). Diurnal variation of sap flow of Robinia pseudoacacia displayed a broadly-peaked curve during the season of rapid growth in the semi-arid region of Loess Plateau, Northwest China (Wu et al., 2010). We found that the diurnal sap flow patterns of $C$. arborescens showed a stepwise morning increase, which to some extent could be related to the capacitance of woody tissue water (Tognetti et al., 2004). A pronounced reduction was observed in the afternoon, which could be related to decreasing temperature and solar radiation. The pronounced high diurnal sap flow in summer might be related to intensive evapotranspiration during the season because plant can maintain water balance by intensive evapotranspiration, and 
avoid over-drying and high temperature burning. The progressive reduction of diurnal sap flow rates in late summer might be related to the shedding of assimilating shoots of $C$. arborescens.

Throughout the course of this study, the sap flow decreased with reducing water regimes. These results are consistent with previous studies in which a decrease in plant transpiration in response to drought stress has been observed (Dünisch and Morais, 2002; Li et al., 2002; Zhao et al., 2003; Tognetti et al., 2004; Huang et al., 2009). Compared with CK, the sap flow of SD was more reduced, which was possibly because the soil moisture content was significantly lower in SD than in CK during the study period.

Nocturnal sap flow is a driving force not only for chemical transport and nutrient movement within plants (McDonald et al., 2002), but also for water recharge driven by diurnal transpiration loss (Daley and Phillips, 2006). Daley and Phillips (2006) found the nocturnal sap flow of Betula papyrifera, Acer rubrum and Quercus rubra functioned as water recharger, and it played as an oxygen supply for the deep cells of Betula papyrifera sapwood. Wang et al. (2007) found it was a nocturnal water recharge phenomenon in Acacia mangium, and the reason was that the transpiration of plants exceeded the water transportation ability of stem during the day, so the roots absorbed soil water during the night and transmitted to supplement water deficit which was caused by diurnal transpiration during the day. Other studies believed that there was low upward sap flow at night in the growing period, which could be due to the lower water potential of above-ground parts of plants. Canopy transpiration during the day mainly resulted from stomatal opening, which produced water potential difference in leaf-canopy-root. The water potential gradient did not disappear immediately with stomatal closure after sunset. Due to a water potential difference, water was passively absorbed through roots and trunks into the leaves, forming a nighttime compensation flow, so trunk water storage was compensated in the night ( $\mathrm{Li}$ et al., 2006). Similar results were found in conifers (Wang et al., 2002) and broad-leaved trees (Lu et al., 2001). In the shelterbelt along the Tarim Desert Highway, water loss during the day cannot be promptly compensated, so there is still some sap flow at night. The high temperature, high air flow and dry- ing air at night may also be responsible for night transpiration ( $\mathrm{Xu}$ et al., 2008a). However, Snyder et al. (2003) argued that the nocturnal sap flow may be considered as representation of sufficient water in the habitat. The nocturnal sap flow of $C$. arborescens raised with increasing irrigation amount, indicating there was higher transpiration intensity under sufficient water supply. This finding is in consistence with Chen et al. (2010), who reported that nocturnal sap flow was larger and more active in rainy than in sunny days. Our study also found that nocturnal sap flow peaked before midnight and dropped to nearly zero afterwards, similar to the patterns for Cedrus deodara, Zelkova schneiderian, Euonymus bungeanus, Metasequoia glyptostroboides, Acacia mangium and Schima superba (Wang et al., 2007; Chen et al., 2010; Zhou et al., 2012). It is possible that water recharge for trunk mainly occurred during the first half of the night, and the steady sap flow during later midnight indicated that the trunk was filled with water after the water supply in first half night. Furthermore, air humidity and low temperatures might be important causes for steady sap flow.

Climatic factors such as air temperature, global radiation and relative humidity are important regulators of transpiration that interact with water availability and the physiological and phenological status of plants, leading to very close correlations between stem sap flow velocity, sap flow flux, and environmental factors (Ortuño et al., 2006; Huang et al., 2009). Hinckiey et al. (1994) found that the variation of sap flow was consistent with the pattern of solar radiation, with a correlation coefficient of more than 0.91 , and meanwhile, atmospheric temperature was also an important factor affecting transpiration intensity. Sap flow velocity of Caragana korshinskii was significantly correlated with solar radiation, relative humidity, air temperature and wind speed, among which solar radiation and relative humidity were two main factors affecting the sap flow velocity (Huang et al., 2011). Zang et al. (2010) found that solar radiation was the key factor affecting the stem sap flow of Caragana intermedia. In the shelterbelt along the Tarim Desert Highway, the dynamics in sap flow under different irrigation treatments coincided with the variation of meteorological factors. The sap flow of $C$. arborescens was significantly affected by net radiation, 
total radiation, air temperature, relative humidity, and wind speed while responding to irrigation treatments. The Brownian movement of water vapour molecules will speed up and kinetic energy will increase when radiation and temperature increase, and the vapour pressure deficit will also increase. The decreased humidity and increased leaf stomatal conductance resulted in plant transpiration increase, thereby leading to an increase in sap flow compensating for the loss of transpiration (Zhang et al., 2007). The seasonal variation in monthly sap flow flux was also consistent with the change trend of major meteorological factors (such as solar radiation and air temperature) and soil moisture content.

Water is a main factor that affects plant growth in the shelterbelt along the Tarim Desert Highway. This study found that plant growth indicators (trunk diameter, twig length and twig diameter) significantly reduced and the growth of $C$. arborescens was limited in SD, which may reduce the stability and sustainability of the shelterbelt. However, little or no significant difference was found in MD compared to $\mathrm{CK}$, meaning that appropriate reduction in the current irrigation amount will not markedly affect plant growth and could be a wiser use of water resources.

\section{Conclusions}

Maintaining the stability and sustainability of the shelterbelt along the Tarim Desert Highway relies on groundwater resources. Our study indicated that water consumption by transpiration decreased under reduced water supply, and the growth parameters also decreased. However, the reduction became significant under stress deficit irrigation, potentially threatening the stability of the shelterbelt. The growth parameters decreased slightly under moderate deficit irrigation, and there was no significant difference between this treatment and the CK. Therefore, we propose that an irrigation amount of $1,960 \mathrm{~m}^{3} / \mathrm{hm}^{2}$ can be recommended for irrigating the shelterbelt along the Tarim Desert Highway without damaging the stability of the shelterbelt while ensuring the most economical use of water resources.

\section{Acknowledgements}

This research was financially supported by the International Science and Technology Cooperation Pro- gram of China (2012DFR30830), the National Natural Science Foundation of China (41261047), the Gansu Science and Technology Support Program (1204NKCA084) and the Project of Knowledge Innovation of the Chinese Academy of Sciences (KZCX3-SW-342).

\section{References}

Baker J M, Van Bavel C H M. 1987. Measurement of mass flow of water in the stems of herbaceous plants. Plant, Cell \& Environment, 10(9): 777-782.

Burgess S S O. 2006. Measuring transpiration responses to summer precipitation in a Mediterranean climate: a simple screening tool for identifying plant water-use strategies. Physiologia Plantarum, 127(3): 404-412.

Campbell G S, Norman J M. 1998. An Introduction to Environmental Biophysics. New York: Springer Science+Business Media, 36-51.

Chen L X, Zhang Z Q, Li Z D, et al. 2010. Nocturnal sap flow of four urban greening tree species in Dalian, Liaoning province, China. Chinese Journal of Plant Ecology, 34(5): 535-546.

Daley M J, Phillips N G. 2006. Interspecific variation in nighttime transpiration and stomatal conductance in a mixed New England deciduous forest. Tree Physiology, 26(4): 411-419.

Dhief A, Gorai M, Aschi-SmitiS, et al. 2009. Comparative phenological and water potential patterns of three Calligonum species in the eastern great Erg of Tunisia. Flora, 204(8): 581-592.

Dragoni D, Lakso A N, Piccioni R M. 2005. Transpiration of apple trees in a humid climate using heat pulse sap flow gauges calibrated with whole-canopy gas exchange chambers. Agricultural and Forest Meteorology, 130(1-2): 85-94.

Dünisch O, Morais R R. 2002. Regulation of xylem sap flow in an evergreen, a semi-deciduous, and a deciduous Meliaceae species from the Amazon. Trees, 16(6): 404-416.

Ferrara G, Flore J A. 2003. Comparison between different methods for measuring transpiration in potted apple trees. Biologia Plantarum, 46(1): 41-47.

Granier A, Huc R, Colin F. 1992. Transpiration and stomatal conductance of two rain forest species growing in plantations (Simarouba amara and Goupia glabra) in French Guyana. Annals of Forest Science, 49(1): 17-24.

Hinckiey T M, Brooks J R, Čermák J, et al. 1994. Water flux in a hybrid poplar stand. Tree Physiology, 14(7-9): 1005-1018.

Huang L, Zhang Z S, Zhou X K. 2011. Stem sap flow of Caragana korshinskii and its influence factors in a revegetated desert area. Journal of Desert Research, 31(2): 415-419.

Huang Y Q, Zhao P, Zhang Z F, et al. 2009. Transpiration of Cyclobalanopsis glauca (syn. Quercus glauca) stand measured by sap-flow method in a karst rocky terrain during dry season. Ecological Research, 24(4): 791-801.

Lagergren F, Lindroth A. 2002. Transpiraton response to soil moisture in pine and spruce trees in Sweden. Agricultural and Forest Mete- 
orology, 112(2): 67-85.

Li H T, Xiang L, Xia J, et al. 2006. Applying the heat dissipation technique to study the sap flow of Pinus elliottii in the red earth area of Subtropical China. Scientia Silvae Sinicae, 42(10): 31-38.

Li J Y, Zhou P, Zhao L J. 2002. Influence of drought stress on transpiring water-consumption of seedlings. Acta Ecologica Sinica, 22(9): $1380-1386$

Lu X Z. 2001. Study on sap flow of Pinus massoniana and Quercus variabilis in growing season. Journal of Anhui Agricultural University, 28(4): 401-404.

McDonald E P, Erickson J E, Kruger E L. 2002. Can decreased transpiration limit plant nitrogen acquisition in elevated $\mathrm{CO}_{2}$ ? Functional Plant Biology, 29(9): 1115-1120.

Moreno F, Fernández J E, Clothier B E, et al. 1996. Transpiration and root water uptake by olive trees. Plant and Soil, 184(1): 85-96.

Ortuño M F, García-Orellana Y, Conejero W, et al. 2006. Stem and leaf water potentials, gas exchange, sap flow, and trunk diameter fluctuations for detecting water stress in lemon trees. Trees, 20(1): 1-8.

Snyder K A, Richards J H, Donovan L A. 2003. Night-time conductance in $\mathrm{C}_{3}$ and $\mathrm{C}_{4}$ species: do plants lose water at night? Journal of Experimental Botany, 54(383): 861-865.

Steinberg S L, Vanbavel C H M, Mcfarland M J. 1989. A gauge to measure mass flow of sap flow in stems and trunks of woody plants. Journal of the American Society for Horticultural Science, 114(3): 466-472.

Su P X, Zhao A F, Zhang L X, et al. 2003. Characteristic in photosynthesis, transpiration and water use efficiency of Haloxylon ammodendron and Calligonum mongolicum of desert species. Acta Botanica Boreal-Occidentalia Sinica, 23(1): 11-17.

Su P X, Yan Q D. 2006. Photosynthetic characteristics of $\mathrm{C}_{4}$ desert species Haloxylon ammodendron and Calligonum mongolicum under different moisture conditions. Acta Ecologica Sinica, 26(1): $75-82$.

Sun P F, Zhou H F, Li Y, et al. 2010. Trunk sap flow and water consumption of Haloxylon ammodendron growing in the Gurbantunggut Desert. Acta Ecologica Sinica, 30(24): 6901-6909.

Tognetti R, d'Andria R, Morelli G, et al. 2004. Irrigation effects on daily and seasonal variations of trunk sap flow and leaf water relations in olive tress. Plant and Soil, 263(1): 249-264.

Vetessy R A, Benyon R G, O’Sullivan S K, et al. 1995. Relation between stem diameter, sapwood area, leaf area and transpiration in a young mountain ash forest. Tree Physiology, 15(9): 559-567.

Walter H, Box E O. 1983. The deserts of central Asia. In: West N E. Temperate Deserts and Semi-deserts. Amsterdam: Elsevier, 193-236.

Wang H, Zhao P, Wang Q, et al. 2007. Characteristics of nighttime sap flow and water recharge in Acacia mangium trunk. Chinese Journal of Ecology, 26(4): 476-482.

Wang H, Zhao P, Cai X A, et al. 2008. Time lag effect between stem sap flow and photosynthetically active radiation,vapor pressure deficit of Acacia mangium. Chinese Journal of Applied Ecology,
19(2): 225-230.

Wang H T, Ma L Y, Sun P S. 2002. Sap flow fluctuations of Pinus Tabulaeformis and Platycladus orientalis in late Autumn. Scientia Silvae Sinicae, 38(5): 31-37.

Wu F, Chen Y M, Yu Z H. 2010. Growing season sap-flow dynamics of Robinia pseudoacacia plantation in the semi-arid region of Loess Plateau, China. Chinese Journal of Plant Ecology, 34 (4): 469-476.

Xie T T, Zhang X M, Liang S M, et al. 2008a. Effects of different irrigations on the water physiological characteristics of Haloxylon ammodendron in Taklimakan Desert Hinterland. Chinese Journal of Applied Ecology, 19(4): 711-716.

Xie T T, Zhang X M, Shan L S, et al. 2008b. Effect of irrigation volume on the water physiological characters and growth of Tamarix ramosissima shelter belts along the Tarim Desert Highway. Arid Zone Research, 25(6): 802-807.

Xu H, Zhang X M, Yan H L, et al. 2008a. Plants water status of the shelterbelt along the Tarim Desert Highway. Chinese Science Bulletin, 53(Suppl. II): 146-155.

Xu H, Zhang X M, Yan H L, et al. 2008b. Water consumption and transpiration of Haloxylon ammodendron in hinterland of Taklimakan Desert. Acta Ecologica Sinica, 28(8): 3713-3720.

Zang C X, Yang J, Yuan J, et al. 2010. Relationships between whole-plant sap flux characteristics of Caragana intermedia and environmental factors in Loess Hill-gully region. Chinese Journal of Ecology, 29(3): 420-426.

Zhang G H, Chen B F, Nie J Z, et al. 2007. Castanopsis jianfengensis sap flow and its relationships with environmental factors in tropical montane rainforest. Chinese Journal of Applied Ecology, 18(4): $742-748$

Zhang J G, Kume T, Otsuki K, et al. 2011. Sap flow dynamics of dominant trees of Quercus liaotungensis forest in the semiarid Loess Plateau region. Scientia Silvae Sinicae, 47(4): 63-69.

Zhang X Y, Kang E S, Zhang Z H, et al. 2005. A study of the stem sap flux of Populus euphratica in the lower reaches of Heihe River. Journal of Glaciology and Geocryology, 27(5): 742-746.

Zhang Z S, Zhang X Y, Tan H J, et al. 2007. Measurement on the transpiration of xerophils in the desert area with steady state porometer and stem heat balance technique. Journal of Beijing Forestry University, 29(1): 60-66.

Zhao L J, Li J Y, Yu J F, et al. 2003. Daily variation in transpiring water-consumption rates of seedlings in different drought stress. Journal of Beijing Forestry University, 25(3): 42-47.

Zhou C M, Zhao P, Ni G Y, et al. 2012. Water recharge through nighttime stem sap flow of Schima superba in Guangzhou region of Guangdong province, South China: affecting factors and contribution to transpiration. Chinese Journal of Applied Ecology, 23(7): 1751-1757.

Zhou X M, Chen Y N, Li W H, et al. 2008. Study of sap flow in stem of Populus Euphratica in lower reaches of Tarim River. Journal of Desert Research, 28(4): 673-678. 